\title{
Pulmonary artery catheter detected in the coronary sinus on intraoperative transesophageal echocardiogram. Diagnosis?
}

\author{
José M. Rodríguez-López • Pilar Sánchez-Conde • \\ Miguel A. Palomero-Rodríguez
}

Received: 23 February 2014/ Accepted: 15 April 2014/Published online: 14 May 2014

(C) Japanese Society of Anesthesiologists 2014

Keywords Pulmonary artery catheter · Coronary sinus . Transesophageal echocardiogram

To the Editor:

A 58-year-old man underwent mitral valve replacement, tricuspid valve repair, and ascending aorta repair.

A pulmonary artery catheter (PAC) was inserted, but transesophageal echocardiography failed to show the PAC in the right atrium: the PAC was traversing an enlarged coronary sinus (Fig. 1). Why? A persistent left superior vena cava (SVC) and agenesis of the right SVC was found.

This is a very rare anomaly: the incidence of persistent left SVC is $0.3-0.5 \%$, and only $18 \%$ of individuals with persistent left SVC also have right SVC agenesis. In $92 \%$ of cases the persistent left SVC drains into the right atrium via the coronary sinus, causing dilation. Coexistent right SVC agenesis further dilates the coronary sinus because of increased venous return [1].

This condition was not noticed preoperatively. Recognizing systemic venous anomalies is key to avoiding complications during central venous catheterization [2].
This case shows the importance of testing for venous abnormalities by performing contrast-enhanced magnetic resonance or venous angiography when an isolated enlarged coronary sinus is found on echocardiography.

Conflict of interest None.

\section{References}

1. Xiong W, Chanjuan S. Concomitant persistent left superior vena cava and agenesis of right superior vena cava. A rare congenital anomaly. Circulation. 2010;121:2329-30.

2. Schummer W, Schummer C, Fritz H. Perforation of superior vena cava due to unrecognised stenosis. Case report of a lethal complication of central venous catheterization. Anaesthesist. 2001;50:772-7.
Electronic supplementary material The online version of this article (doi:10.1007/s00540-014-1838-2) contains supplementary material, which is available to authorized users.

J. M. Rodríguez-López ( $₫)$ · P. Sánchez-Conde .

M. A. Palomero-Rodríguez

Servicio de Anestesiología, Hospital Universitario de

Salamanca, Paseo de San Vicente, 58-182, 37007 Salamanca,

Spain

e-mail: jmrodlop@yahoo.com 